\title{
Spatiotemporal features of pollutant loads in the Yan River Basin, a typical loess hilly and gully watershed in the Chinese Loess Plateau
}

\author{
Yanni Song ${ }^{1,2}$, Yiping $\mathrm{Wu}^{1,2^{*}} \mathbb{D}$, Changshun Sun ${ }^{3}$, Fubo Zhao ${ }^{1}$, Jingyi $\mathrm{Hu}^{1}$, Ji Chen ${ }^{4}$, Linjing Qiu ${ }^{1}$ and
} Yanqing $\operatorname{Lian}^{5}$

\begin{abstract}
Water quality is the restrictive factor for both ecosystem health and social development in the Chinese Loess Plateau, a unique area with most severe soil erosion, fragile ecology, and water shortage. Understanding the characteristics of the pollutant loads is of vital importance for the sustainability of eco-environment in the Loess Plateau. This study investigated the spatiotemporal changes of chemical oxygen demand (COD), total nitrogen (TN), and total phosphorus (TP) loads by combining the Soil and Water Assessment Tool (SWAT) and regression model Load Estimator (LOADEST) in a typical loess hilly and gully watershed - the Yan River Basin (YanRB). Results showed that the model simulations of monthly streamflow and pollutant loads were in good agreement with those derived from the in situ observations. The temporal variation analysis suggested that the pollutant loads were generally rising in the study period (2001-2018) at four of the five stations and reached the maximum in 2014, and the multi-year (i.e., 2001-2018 with 2013 being excluded due to extreme rainfall) average loads of COD, TN, and TP at the Tanjiahe station, which is close to the outlet of the basin, were 15,021 kg/day, $3835 \mathrm{~kg} /$ day, and $168 \mathrm{~kg} /$ day, respectively. The spatial distribution of the TN and TP loads along the river seemed to be quite unique because the TP level were obviously higher at the midstream (e.g., Zhujiagou and Ganguyi) than the downstream (e.g., Tanjiahe), and the TN level decreased when the river flowed from Zhujiagou to Ganguyi. Further, the seasonal analysis indicated that the nutrient loads were the highest in summer, followed by autumn, and the loads in these two seasons contributed the most of the annual pollution loads-about 76\% and 84\% for TN and TP, respectively, indicating the higher flow, the higher pollution load, a similar point based on the inter-annual analysis. In addition, the contribution analysis of point source and non-point source pollutions demonstrated that NPS led to most of the pollutant loads at the whole watershed $-70 \%, 67 \%$, and $71 \%$ of the COD, TN, and TP loads, respectively. Overall, this study provided spatiotemporal distributions of the key pollutant loads in the YanRB and can be valuable for water quality protection and pollution control in this area.
\end{abstract}

Keywords: Chemical oxygen demand, Nutrient loads, Load estimator, Non-point source pollution, Soil and water assessment tool

\footnotetext{
*Correspondence: rocky.ypwu@gmail.com

${ }^{1}$ Department of Earth and Environmental Science, Xi'an Jiaotong University, Xi'an 710049, Shaanxi Province, China

Full list of author information is available at the end of the article
}

\begin{abstract}
Introduction
Pollutant discharge causes widespread organic pollution and eutrophication, along with severe ecological destruction, and further threats human health and agricultural production (Wang and Yang 2016; Dai et al. 2017; Lang et al. 2013; Schwarzenbach et al. 2010). The Chinese
\end{abstract}

\section{Springer Open}

(c) The Author(s) 2022. Open Access This article is licensed under a Creative Commons Attribution 4.0 International License, which permits use, sharing, adaptation, distribution and reproduction in any medium or format, as long as you give appropriate credit to the original author(s) and the source, provide a link to the Creative Commons licence, and indicate if changes were made. The images or other third party material in this article are included in the article's Creative Commons licence, unless indicated otherwise in a credit line to the material. If material is not included in the article's Creative Commons licence and your intended use is not permitted by statutory regulation or exceeds the permitted use, you will need to obtain permission directly from the copyright holder. To view a copy of this licence, visit http://creativecommons.org/licenses/by/4.0/. 
government has realized the importance of controlling water pollution, and published Action Plan for Prevention and Control of Water Pollution to protect the surface water and groundwater in April 2015 (Shi et al. 2015). However, making efficient water quality management measures is difficult because of multiple anthropogenic and natural influencing factors. According to the statistical data, the increase rate of wastewater and sewage discharge is 1.8 billion $\mathrm{m}^{3}$ per year, and the daily discharge of industrial and domestic wastewater in China is about 164 million $\mathrm{m}^{3}$ (Zhou and Li 2018). Besides, Zou et al. (2020) used an inventory analysis to estimate the agricultural non-point source (NPS) pollution loads from 1978 to 2017 in China, and found that the pollution loads of chemical oxygen demand (COD), total nitrogen (TN) and total phosphorus (TP) increased by $91.0 \%, 196.2 \%$, and $244.1 \%$, respectively. Therefore, identifying the current pollution situation and understanding its relationships with human activities are important for water resources protection and pollution control.

Hydrometeorological factors (e.g., precipitation, runoff, and temperature), anthropogenic factors (e.g., land use, agricultural practices), and geographical factors (e.g., soil, vegetation, slope gradient) can largely affect the formation and transformation of pollutants. There were a number of studies assessing the water quality issues in recent years, especially about nutrients (e.g., TN, TP) and sediment loads, urbanization, and reservoir operation (Xia et al. 2020; Oelsner and Stets 2019; Tong et al. 2015). Numerical water quality models are useful tools for evaluating pollution loads at the watershed scale, and these models can be divided into classical empirical models (e.g., RUSLE, SEDD, and PLOAD), statistical models (e.g., SPARROW, WRTDS, and GAMMKS), physically based models (e.g., SWAT, ANSWERS, and AnnAGNPS), and intelligent data analysis methods such as Hybrid Double Feedforward Neural Network and Fuzzy Binary Comparison methods (Lin et al. 2016, 2018; Zou et al. 2020). The Soil and Water Assessment Tool (SWAT) model has been widely used to simulate the sediment and nutrient load transport through surface runoff, lateral flow, and groundwater flow (Chen et al. 2012). However, the applications of SWAT in some regions are often disabled due to the data shortage. Jiang et al. (2019) proposed the Hydro-Informatic Modelling System-pollution load (HIMS-PL) model to simulate the processes of pollutant generation and transport, and quantified the pollution load in semiarid and semi-humid areas. However, this model needs intensive input data including the spatial attribute information of study area, meteorology, streamflow, point source (PS) pollutant loads, and cross-section pollutant concentrations. The Load Estimator (LOADEST) model, which has been widely used for quantitative assessment of pollution loads in those ungauged watersheds or those with limited gaging watershed, has been proven to be an efficient tool in water quality assessment (Duan et al. 2013; Chen et al. 2015a, 2017).

Pollutants can be classified as PS and NPS pollution. PS pollution is relatively easy to manage and control because it is easy to be monitored, but it is quite difficult to quantify NPS pollution load and determine its pollutions sources because NPS is inseparable from precipitation, snowmelt, runoff, and soil erosion processes. Some studies have proposed methods for estimating NPS pollution loads (Li 2000; Hao et al. 2006), mainly including multivariate statistical analysis, dual stable isotopes, hydrological and water quality watershed models, geographical information systems (GIS) technology, and hydro-chemical characteristic analysis (Wei et al. 2020). In these methods, the statistical method has been widely used to analyze the relationships between flow and concentration (Wang et al. 2015; Li et al. 2011).

The organic pollution, excessive nutrients (e.g., nitrogen and phosphorus), and heavy metal pollution are important components of water pollution (Zeng et al. 2021). In particular, the rapid economic development in Northwest China has led to substantial imbalances between the natural environment and industrial development. The Loess Plateau, mainly located in the middle reach of the Yellow River, is considered as one of the regions with the most severely eroded areas in the world, and the soil loss has significantly impacted nutrient losses (Zhao et al. 2020a). Further, the Yellow River is facing the problem of water quality deterioration with the rapid development of the social economy. It was reported that the water quality in almost $34.8 \%$ of main tributaries (e.g., the Qingjian, the Fen, the Shiwang, and the Yan Rivers) were generally below Class III standard (GB3838-2002), and the main pollutants were COD, ammonia nitrogen, and TP. Zhao et al. (2020b) pointed that the most polluted areas were concentrated in the midstream of the Yellow River, and there will be a long-term and arduous task to control the pollution of river. The Yan River, a typical tributary of the Yellow River, is located in the Loess Plateau. The ecological environment of the watershed is very vulnerable, and in particular, the water quality has deteriorated dramatically (Yang et al. 2019; Chen et al. 2020). One reason for the water quality degradation is the substantial reduction of streamflow and the resulting decreased self-purification capacity of the river (Pei et al. 2019; Junfu et al. 2016). Another reason is the increased discharge of wastewater to the Yan River.

Although there were some references about water pollution of the Yan River (Pei et al. 2019; Wu et al. 2017; Wu et al. 2019; Junfu et al. 2016; Deng et al. 2018), few studies focused on pollutant flux analysis under 
the combined effects of natural and human activities. Besides, the field experimental studies could not meet the requirements of long-term and large-scale water quality analysis due to its difficulty and cost. Therefore, it is promising to use mathematical models to investigate the spatiotemporal patterns of pollutant loads for supporting effective water quality management. However, some models are difficult to analyze water pollution problems with insufficient data, so we combined the advantages of the SWAT and LOADEST model to increase the data and evaluate the pollutant loads in the Yan River Basin (YanRB). Furthermore, in order to further clarify the characteristics of pollutant emissions, we used statistical method to quantify PS and NPS load when data were scarce. Based on these methods, the specific objectives of this study were to: (1) estimate the loads of the key pollutants (COD, TN and TP) at the main cross-sections of the river; (2) quantify the contributions of PS and NPS pollution to the total pollution load; (3) investigate the transport of pollutants along river under different hydrological conditions.

\section{Materials and methods Study area}

The Yan River originates from Baiyu Mountain and flows from northwest to southeast through Zhidan, Ansai, Yan'an, and Yanchang counties before entering the Yellow River. The length of the river is $286.9 \mathrm{~km}$, and the drainage area is $7725 \mathrm{~km}^{2}$ (Wu et al. 2020) (Fig. 1). The annual average air temperature of the basin ranged from $7.9{ }^{\circ} \mathrm{C}$ in the west to $10.6{ }^{\circ} \mathrm{C}$ in the east. The annual average precipitation is between 340 and $660 \mathrm{~mm}$ across the basin. The primary soil type is loessial soil, accounting for $85 \%$ (Lian et al. 2021). Besides, the short-duration and high-intensity precipitation led to about $60.5 \%$ of the runoff occurring in the wet season, especially in July through September, and caused intensive soil erosion (Miao 2018). In the YanRB, there are three dominate land use types-grassland, cropland, and woodland, accounting for $55.1 \%, 17.64 \%$, and $26.16 \%$ of the basin, respectively.

Energy (e.g., oil and coal) is the dominant industry of the YanRB and has exerted a profound influence on the economic development. Major agricultural products in this area include apple, greenhouse vegetables, Oryza sativa, and strawberries (Su et al. 2011), and the fertilization is quite intensive, leading to relatively higher nutrient loss to the river. We chose five cross-sections-Ansai in the upstream, Shiyaocun, Zhujiagou, and Ganguyi in the middle stream, and Tanjiahe in the downstream (Fig. 1) - to analyze the features of pollutant loads along the main river.

\section{Model description \\ SWAT}

The Soil and Water Assessment Tool (SWAT) model, developed by the Agricultural Research Service of the United States Department of Agriculture (USDA-ARS), is a comprehensive hydrological and water quality model (Arnold et al. 1998; Neitsch et al. 2011). SWAT takes spatially variable soil and land cover conditions into consideration to delineate the watershed. The Hydrological Response Units (HRUs) are the basic and least computing units that possess unique land use, soil property, and slope. The main outputs of SWAT are surface runoff, lateral flow, baseflow, evapotranspiration, water yield, sediment load, nutrient loads, etc.

The SWAT model was designed for long-term continuous simulations at daily time step for watershed management decisions (Sudheer et al. 2007). In this study, we used the Sequential Uncertainty Fitting version 2 (SUFI-2) algorithm to optimize the parameters, and the calibrated/validated SWAT was used to obtain the long-term streamflow, which were then used for subsequent pollutant load estimation with LOADEST (see the following section). Based on the sensitivity analysis, we identified eight parameters and derived the optimal values using SUFI2 (Table1).

\section{LOADEST}

The Load Estimator (LOADEST) is an empirical statistical model, developed by the United States Geological Survey (USGS) and can estimate the long-term pollutant loads using the streamflow and pollutant concentration regression relationships (Sharifi et al. 2017). The setting of the model requires at least 12 continuous flows and concentration data (Park and Engel 2016). Considering the different diffusion modes of pollutants and the adaptability of pollutant loads to river dynamics, 11 regression equations are available to users in the LOADEST. The model uses Tobit regression to process the discrete water quality and streamflow data at the monitoring point and automatically selects the predefined model through the lowest Akaike information criterion (AIC) and the Schwarz posterior probability criterion (SPPC) (Runkel et al. 2004).

The model parameter estimation is established based on three statistical algorithms, including the adjusted maximum likelihood estimation (AMLE), the minimum variance unbiased estimate (MVUE), and the least absolute deviation (LAD) method. This study selected the AMLE estimation method, which can eliminate the influence of censored data as much as possible and has been proven to have a high simulation accuracy 




Table 1 Sensitive parameters and optimized values of SWAT using SUFI-2

\begin{tabular}{llll}
\hline Parameter & Description & Range & Optimized value \\
\hline CN2 & SCS runoff curve number & $-10-10 \%$ & $3.8 \%^{*}$ \\
ALPHA_BF & Base flow alpha factor (day) & $0-0.5$ & 0.37 \\
SOL_K & Saturated hydraulic conductivity $(\mathrm{mm} / \mathrm{h})$ & $0-5$ & 3.76 \\
SOL_AWC & Available water capacity of the soil layer $(\mathrm{mm})$ & $-30-30 \%$ & $25 \%^{*}$ \\
SLSUBBSN & Average slope length $(\mathrm{m})$ & $0-55$ & 51.28 \\
ESCO & Soil evaporation compensation factor & $0-1$ & 0.82 \\
CH_K2 & Effective hydraulic conductivity in the main channel $(\mathrm{mm} / \mathrm{h})$ & 43 \\
GWQMN & Threshold depth of water in the shallow aquifer required for return flow to & $100-1000$ & 567.7
\end{tabular}


(Aulenbach 2013; Duan et al. 2014). The specific principle of the AMLE is described as follows (Cohn et al. 1992):

$$
\hat{L}_{\mathrm{AMLE}}=\exp \left(a_{0}+\sum_{j=1}^{M} a_{j} X_{j}\right) H\left(a, b, s^{2}, \alpha, \kappa\right),
$$

where $\widehat{L}_{\mathrm{AMLE}}$ is the AMLE estimate of instantaneous load, $a$ and $b$ are functions of the explanatory variables, $\kappa$ and $\alpha$ are parameters of the gamma distribution, $s^{2}$ is the residual variance, $a_{0}$ and $a_{j}$ are maximum likelihood estimates corrected for first-order bias, the bias correction factor $\left[H\left(a, b, s^{2}, \alpha, \kappa\right)\right]$ is an approximation of the infinite series.

\section{Data}

The main input data for SWAT include digital elevation model (DEM), soil, land use, and meteorological data. The DEM data with a 30-m resolution was obtained from the National Geomatics Center (http://www.ngcc.cn/ ngcc/). Land use data in 2010 with $30 \mathrm{~m}$ resolution were provided by the Institute of Remote Sensing and Digital Earth, Chinese Academy of Sciences. Meteorological data (1951-2018) were collected from the Data Center of the China Meteorological Administration (http://data. $\mathrm{cma} . \mathrm{cn} /$ ), including precipitation, relative humidity, wind speed, maximum, and minimum air temperature. The solar radiation was estimated based on sunshine duration data, and the calculation details are available in our previous study (Zhang et al. 2019). The observed monthly runoff data (2001-2008) at the Ganguyi flow gaging station, with a drainage area of $5891 \mathrm{~km}^{2}$, were obtained from the Yellow River Water Resources Commission.

In this study, the in situ observed runoff data were only available for Ansai, Yan'an, Ganguyi flow gaging stations, covering the period of 2015-2018, and the runoff data for the other periods (2001-2014) were from SWAT simulations. Water quality data (2017-2018) including chemical demand oxygen (COD), total nitrogen (TN), and total phosphorus (TP) concentration at five monitoring stations were obtained from the water quality monitoring station, with TN missing from January through June in 2017.

\section{Model setup and verification}

The ArcSWAT (version 2012) was used to prepare the model input for driving SWAT to simulate the streamflow of the YanRB. Based on the combination of land use, soil, and slope, the YanRB was discretized into 99 sub-basins and 686 HRUs. We used the SWAT-CUP (SWAT Calibration and Uncertainty Programs) program to optimize the model parameters. The correlation coefficient $\left(R^{2}\right)$, Nash efficiency coefficient (NSE), and percent bias (PBIAS) were selected to quantify the fitness between the measurements and simulations. Theoretically, model simulation is rated satisfactory when $R^{2} \geq 0.5, \mathrm{NSE} \geq 0.5,-25 \% \leq$ PBIAS $\leq 25 \%$ according to Moriasi et al. (2007) (see "Appendix").

In this study, we used flow and water quality data (i.e., COD, TN, and TP) as input for the LOADEST model. Then, we set up a few key variables of interest (e.g., observed date, time, streamflow, and concentration) for LOADEST to generate the long-term series of each key variable based on the optimal equations. Finally, the fitness of the best candidate equation was validated by comparing observed and simulated loads. A few statistical terms, including $R^{2}$, NSE, PBIAS, and the probability plot correlation coefficient (PPCC), were used to evaluate the model performance when selecting the final equation for estimating constituent loads.

\section{Quantification of PS and NPS pollutant loads}

As a statistical method, the characteristic load method has received much attention, especially in areas where there is no continuous monitoring data (Zhu et al. 2012). This method is based on the assumptions that the pollutant load in the dry season is predominantly contributed by the PS, and NPS pollution load mainly comes from the rainfall-runoff process. Therefore, the adoption of this method assumed that the discharge of PS pollution load remains stable in a year, and the monthly PS load of a certain pollutant can be estimated based on pollutant concentration and streamflow during the dry season (December-March). The annual PS load can be calculated with the following equation (Zhu et al. 2018):

$$
L_{\text {ppy }}=12 * \operatorname{Min}\left(C_{\mathrm{pi}} * Q_{\mathrm{pi}}\right),
$$

where the annual PS pollution load $L_{\text {ppy }}$ can be determined by the minimum value of the pollutant concentration $C_{\mathrm{pi}}$ multiplied by the average flow $Q_{\mathrm{pi}}$ in the dry season.

$$
L_{\mathrm{ty}}=\sum_{i=1}^{12} C_{i} * Q_{i},
$$

where $L_{\text {ty }}$ is the total pollution load of a specific pollutant (e.g., TN) in the river channel, $C_{i}$ is observed pollutant concentration in the $i$ th month, and $Q_{i}$ is the average streamflow in the $i$ th month.

$$
L_{\mathrm{nppy}}=L_{\mathrm{ty}}-L_{\mathrm{ppy}} .
$$

The annual NPS pollution load $L_{\text {nppy }}$ equals the total pollution load minus the point source pollution load. 


\section{Results}

Model performance evaluation Hydrological modeling

Figure 2 shows the visual comparison of simulated monthly streamflow against the observations at the Ganguyi flow gaging station. Although there was an underestimation of streamflow during the wet season, the overall performance was satisfactory during both calibration (2001-2004) and validation (2005-2008) periods, with $\mathrm{R}^{2}$ and NSE ranging from 0.50 to 0.67 and PBIAS being less than $15 \%$. According to the evaluation standard by Moriasi et al. (2007), the model performance in streamflow simulation can be rated as satisfactory.

\section{Water quality model evaluation}

The LOADEST simulated and observed COD, TN, and TP loads with the 95\% confidence interval at Ganguyi water quality monitoring station during 2017-2018 are shown in Fig. 3a, c, and e. Although the model underestimated the peak values in July, it can still capture the temporal patterns of the three pollutants. To further evaluate the model performance, the scatter plots (Fig. 3b, d, and f) showed that the $R^{2}$ was above 0.69 , NSE was above 0.56 , and |PBIAS| was lower than $25 \%$ for the COD, TN and TP loads. Besides, we found that the estimation of TN and TP loads had a better performance than COD. For five water quality monitoring stations, the statistical evaluation terms showed that the modeling loads of COD, TN, and TP had good performances, with the $\mathrm{R}^{2}$ ranging from 0.52 to 0.94 , the NSE ranging from 0.49 to
0.90 , the PBIAS ranging from -6.9 to $-24.1 \%$, and the PPCC ranging from 0.88 to 0.99 (Table2). Overall, the model can accurately simulate the pollutant loads in the YanRB.

\section{Spatiotemporal distribution of pollutant loads Annual pollution loads in the YanRB}

Figure 4 demonstrates the monthly average loads of COD, TN, and TP at five stations from 2001 to 2018, excluding 2013. The pollutant loads fluctuated greatly within a year because precipitation dominated the pollutant delivery. For example, the COD load on January 2018 was 5,241 kg/day and 27,336 kg/day for July in 2018. We also found both TN and TP load at Ganguyi, a station in the middle reach, exceeded the final cross-section (i.e., Tanjiahe) during 2017-2018. From Additional file 1: Fig. S1, we found that the annual average loads of COD, TN and TP were relatively stable before 2009, and there was a slight upward trend for COD and TP loads at four of the five stations (i.e., Ansai, Shiyaocun, Ganguyi, and Tanjiahe) during the 17-year study period, though the trend was not statistically significant. Further, there was a decreasing trend in annual average pollutant loads at the Zhujiagou station. Specifically, the annual average COD load changed from $9815 \mathrm{~kg} /$ day in 2001 to $5213 \mathrm{~kg} /$ day in 2018 (about 47\% decrease), annual average TN load decreased from $3002 \mathrm{~kg} /$ day in 2001 to $1852 \mathrm{~kg} /$ day in 2018 (about 38\% decrease), and annual average TP load declined from $88 \mathrm{~kg} /$ day in 2001 to $50 \mathrm{~kg} /$ day in 2018 (about $43 \%$ decrease). In addition, the temporal variation
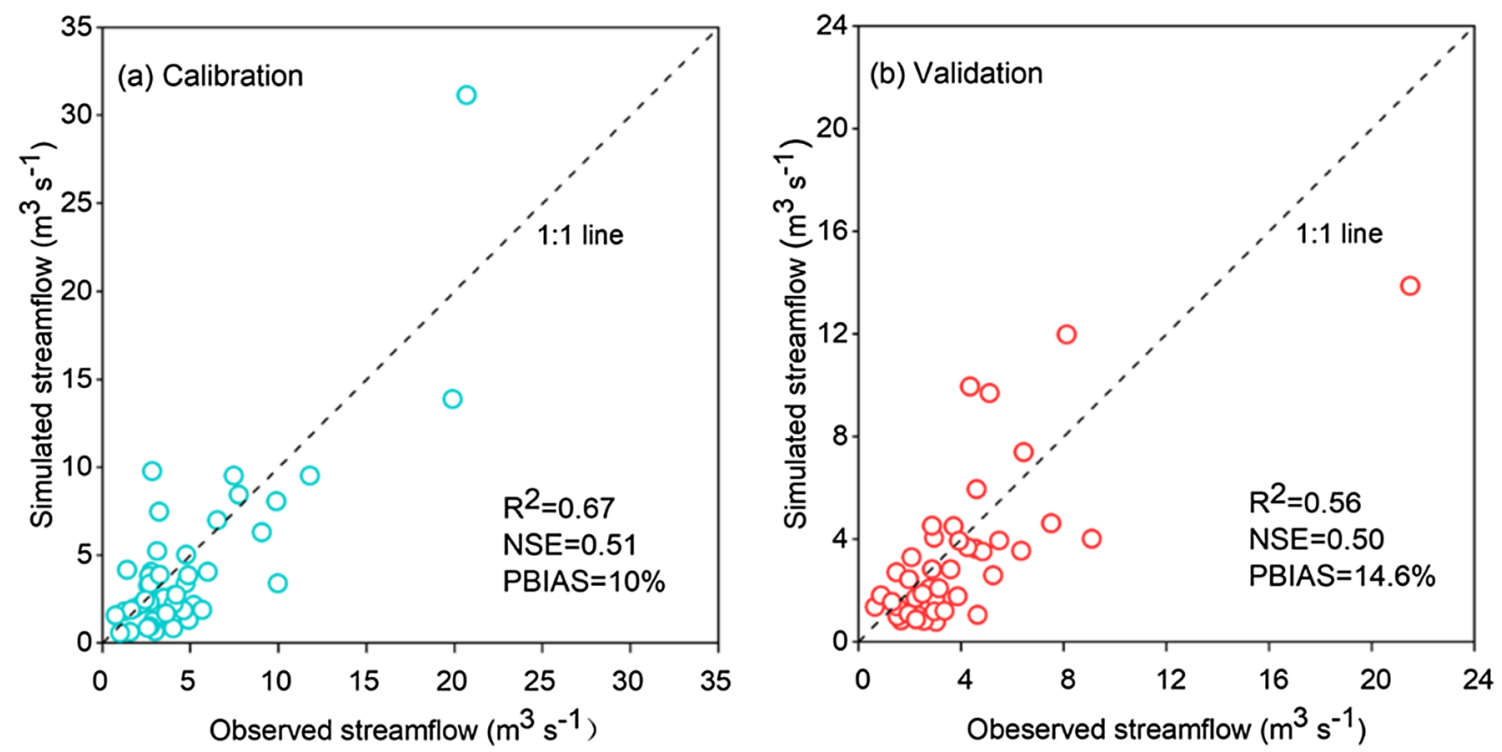

Fig. 2 Evaluation of the model performance in streamflow simulation at the Ganguyi gaging station during the 4-year (2001-2004) calibration and 4-year (2005-2008) validation periods 

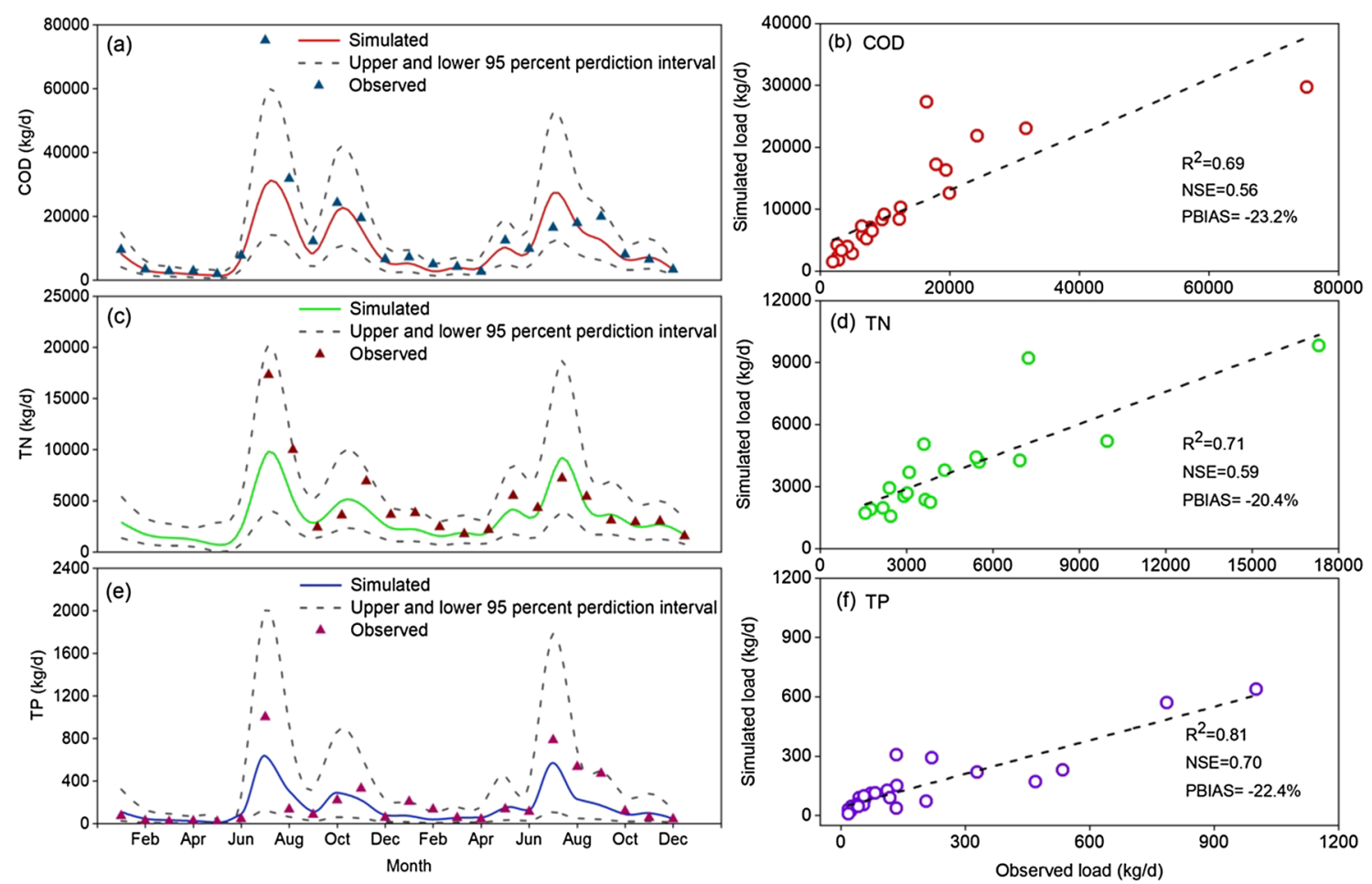

Fig. 3 Comparison of the simulated versus the observed COD (a and $\mathbf{b}$ ), TN (c and $\mathbf{d}$ ), and TP (e and $\mathbf{f}$ ) loads. The scatterplots on the right panel represent comparisons between observed and simulated loads

Table 2 Evaluation of LOADEST performance in simulating COD, TN, and TP loads

\begin{tabular}{llllll}
\hline $\begin{array}{l}\text { Monitoring water } \\
\text { quality stations }\end{array}$ & Pollutants & $\mathbf{R}^{\mathbf{2}}$ & NSE & PBIAS (\%) & PPCC* \\
\hline Ansai & COD & 0.94 & 0.90 & -15.1 & 0.88 \\
& TN & 0.78 & 0.64 & -18.9 & 0.95 \\
Shiyaocun & TP & 0.78 & 0.62 & -24.1 & 0.98 \\
& COD & 0.76 & 0.71 & -17.7 & 0.99 \\
& TN & 0.67 & 0.60 & -15.3 & 0.96 \\
Zhujiagou & TP & 0.72 & 0.70 & -14.7 & 0.99 \\
& COD & 0.84 & 0.80 & -16.4 & 0.98 \\
& TN & 0.58 & 0.54 & -17.3 & 0.97 \\
Ganguyi & TP & 0.52 & 0.51 & -6.9 & 0.97 \\
& COD & 0.69 & 0.56 & -23.2 & 0.95 \\
& TN & 0.71 & 0.59 & -20.4 & 0.98 \\
Tanjiahe & TP & 0.81 & 0.70 & -22.4 & 0.97 \\
& COD & 0.73 & 0.6 & -14 & 0.99 \\
& TN & 0.58 & 0.49 & -13 & 0.98 \\
& TP & 0.58 & 0.53 & -14.6 & 0.98
\end{tabular}

*PPCC: probability plot correlation coefficient

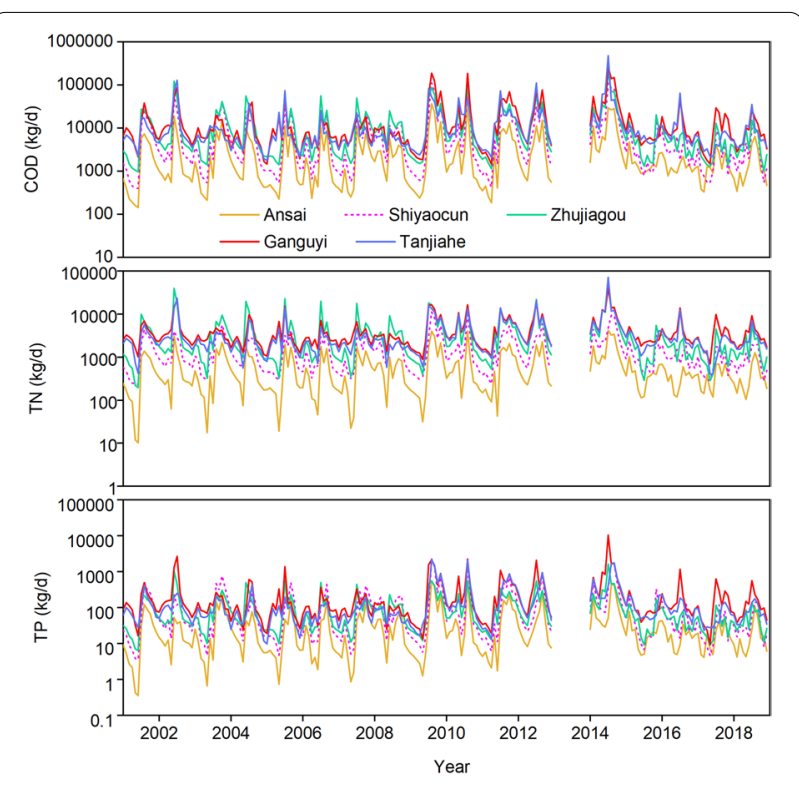

Fig. 4 Estimated monthly average loads of COD, TN, and TP at five stations along the mainstream of the Yan River 
showed that the pollutant loads were generally rising and reached the maximum in 2014, and the trend was statistically significant at four of the five stations (i.e., Ansai, Shiyaocun, Ganguyi, and Tanjiahe station).

\section{Monthly pollution loads in the YanRB}

Figure 5 shows the multi-year average loads of COD, TN, and TP in each calendar month at five stations from 2001 to 2018, excluding 2013. It can be seen that the monthly distribution of pollutant loads is very uneven, and the maximum value occurred in July. The spatial distribution of the COD loads increased from upstream to downstream of the river, reflecting that the transportation and confluence of COD pollutant with streamflow. The TN loads decreased when river flowed from Zhujiagou to Ganguyi station, and this was mainly caused by relatively more intensive agricultural practices such as fertilization and flooding irrigation. The spatial feature of the TP loads along the river seemed to be quite unique because the TP level was obviously higher at the Zhujiagou and Ganguyi station in the midstream than that at the Tanjiahe in the downstream.

\section{Seasonal pollution loads in the YanRB}

Estimated seasonal loads of TN and TP at five water quality monitoring stations were highly variable in the YanRB. The result showed that the greatest loads occurred in

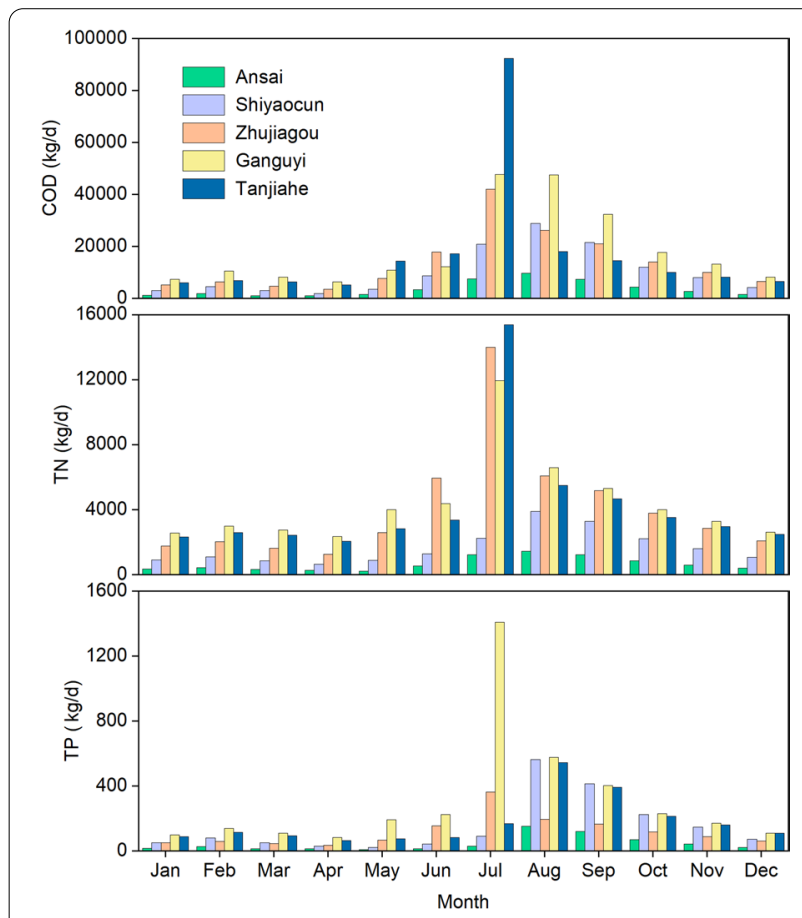

Fig. 5 Estimated multi-year average loads of COD, TN, and TP in each calendar month at five stations in the Yan River Basin summer due to high streamflow, followed by autumn, and the loads in these two seasons contributed the most of the annual pollution load-about $76 \%$ and $84 \%$ for TN and TP, respectively, reflecting the effect of seasonal runoff patterns and agricultural practices on pollution loads (Fig. 6). The multi-year average proportion of TP loads in summer was $52 \%$, a little higher than that of $\mathrm{TN}$ loads (49\%). Compared to Ganguyi, the proportion of the TN loads in summer at Zhujiagou were significantly higher, which might be attributed to relatively larger farmland areas around Zhujiagou (see Fig. 1). Therefore, it should be noted that the YanRB might face the challenge of eutrophication in summer and the nutrient losses due to the intensive agricultural practices in autumn.

\section{Contributions of PS and NPS pollution loads}

The different water quality data sources, and hydrological separation methods caused largely uncertainty for the investigation of NPS pathways (Zhu et al. 2019). Figure 7 shows the contributions of NPS pollution load to the total pollution loads. Our spatial analysis showed
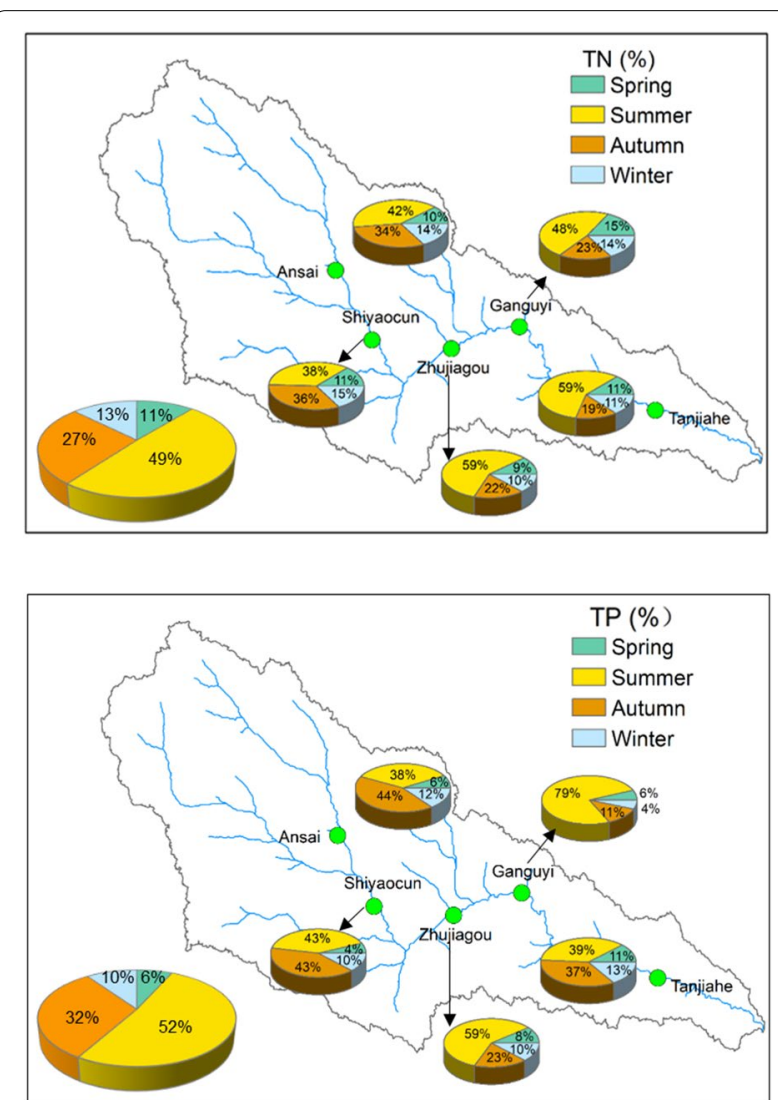

Fig. 6 The multi-year average proportions of TN and TP loads in each season at five water quality monitoring stations. The big pie charts represent the multi-year average proportions of TN and TP, respectively 

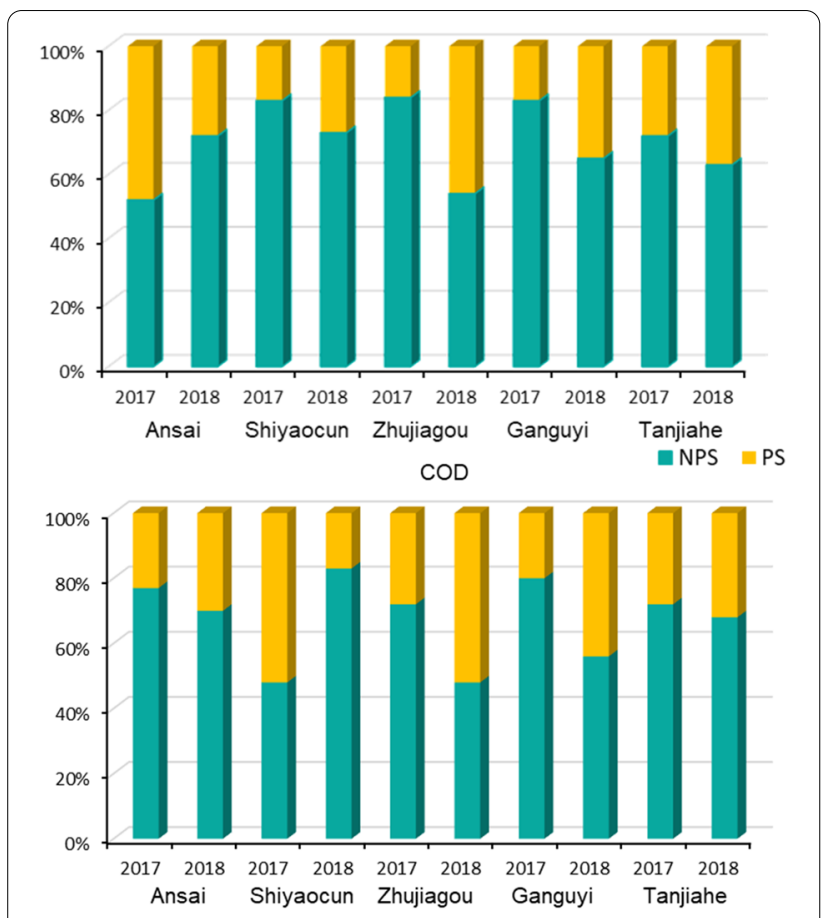

TN

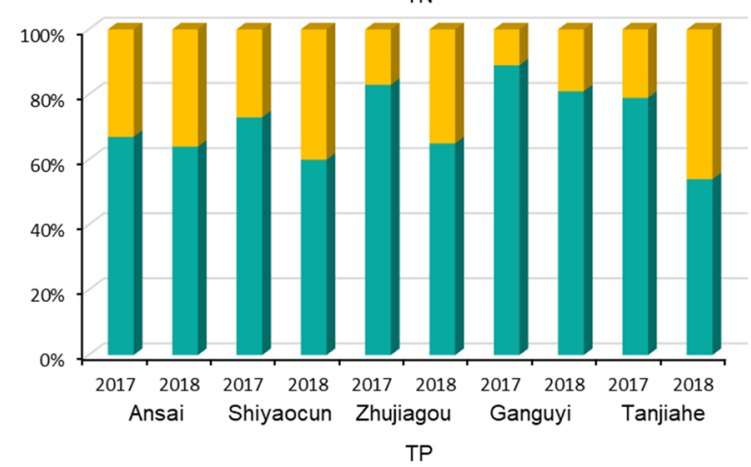

Fig. 7 The contributions of PS and NPS pollutant loads at five water quality monitoring stations

that the COD pollution load increased from upstream to downstream in 2017-2018, and the annual COD load of Tanjiahe station was $3552 \mathrm{t}$, which was mainly contributed by NPS pollution. Compared with other stations, the PS of Ansai and Zhujiagou contributed more to the total COD load, reaching $48 \%$ and $46 \%$, respectively. The TN pollution load was dominated by NPS, but the PS TN pollution of Shiyaocun in 2017 was 52\%, and the PS TN pollution of Zhujiagou and Ganguyi in 2018 accounted for $52 \%$ and $44 \%$, respectively. Therefore, although NPS pollution dominated the overall TN load, PS management should not be ignored. Based on the estimated TP pollution load, the percentage of NPS was $54-88 \%$, while PS was $12-46 \%$ of the total load, indicating that the contribution of NPS to TP was relatively higher.

\section{Discussion}

\section{Water pollution features}

In the YanRB, the PS pollution mainly comes from industrial and domestic wastewater, whereas NPS pollution mainly comes from agriculture, livestock, and poultry breeding, and large-scale oil and coal mining. From Fig. 4, we found that this watershed was more seriously polluted by the organic pollutants, which probably mainly come from oil and coal mining, livestock, and poultry breeding. The spatial distribution of TP loads along the river showed that the maximum was at Ganguyi, a station in the middle reach, followed by a sharp decrease at Tanjiahe (a station closes to the estuary). One reason is that the slope of the river channel in the downstream area (after Ganguyi) became less, and the river velocity became lower with reduced hydraulic condition, causing the deposition of phosphorus with sediment. Another reason can be the check dams in gullies/channels and few tributaries in the downstream, leading to the intercept and adsorption of phosphorus during its transport in channels (Sun et al. 2019; Guo et al. 2016). Overall, the spatial distribution of nutrients exhibited a non-linear change from upstream to downstream, and this phenomenon can be attributed to various cumulative effects (USEPA 2015) such as different hydrodynamic conditions, population density, topography, and the intensive cultivation in some specific areas. Moreover, the meteorological, hydrological, and underlying surface conditions are also important influencing factors in the spatiotemporal characteristics of pollution in the loess hilly and gully. Wu et al. (2016) found that the distributions of NPS pollution load and sediment yield are closely related to land use types and soil erosion of the Majiagou watershed, one sub-basin of the YanRB. In our study area, the farming practices such as fertilization and tillage exerted great influences on TN and TP loads in middle areas.

With respect to management of this region, our results showed that the three stations (i.e., Shiyaocun, Zhujiagou, and Ganguyi) locating in the Baota district contributed most to the pollutant loads, which was in agreement with the study by Wu et al. (2015). Therefore, it is significant to pay much attention to this area for pollution control. In addition, we found that the pollutant loads at Ganguyi were the highest (i.e., higher than that of Tanjiahe which was close to the estuary), and thus the area around Ganguyi has become a highly polluted area in recent years. Therefore, application of potential measures (e.g., riparian filter zone, drip irrigation technology, hyperaccumulator plants in farmland zone) in this area would be cost-effective. Furthermore, effective treatment technologies and management of industrial and municipal wastewater are also important 
to alleviate the deterioration of the river water quality (Wu and Chen 2013).

\section{Implications of the flood-pollution loads relationship} In previous studies on pollution of the Yan River, experimental approaches were used to investigate sediment and nutrient losses due to erosion at the slope scale, and little attention was paid to the changes of COD, TN, and TP under different hydrological conditions, though these pollutants caused adverse effects on the aquatic ecosystem. During our study period, an extremely heavy rainstorm occurred in 2013, which caused a rapid surface flow, creating and reshaping the dispersal pollutant patterns in a river system (Grygar et al. 2014). It is noted that an extreme rainfall event can affect the statistical trend analysis of the pollution load at the annual or monthly scale. Therefore, we excluded an extremely high water year (2013) when investigating annual/seasonal average characteristics of pollutant loads, as shown in "Spatiotemporal distribution of pollutant loads" section. To illustrate the difference of the pollutant loads in extreme and normal hydrological condition, Fig. 8 compares the pollutant loads during 2013 and averaged loads across other years (i.e., 2001-2012 and 2014-2018) at four stations (i.e., Shiyaocun, Zhujiagou, Ganguyi, and Tanjiahe). The spatial analysis indicated that the impact of the high-intensive rainfall on the downstream (from Ganguyi to Tanjiahe) was great due to the confluence of the river tributaries in 2013, suggesting the severe threat of flooding events to the aquatic environment. It has been recognized that pollutant fluxes were very large during an extreme year because the pollutants temporarily stored in channels or slope lands are quickly entrained and transferred during floods (Chen et al. 2015b). For example, the average value of COD was $155,683 \mathrm{~kg} /$ day at Ganguyi during 2013, which is nearly 9 times the average load $(18,211 \mathrm{~kg} /$ day $)$ across other years. Our study demonstrated that more attention should be paid to the impacts of the extreme hydrological year on water quality for developing cost-effective prevention and controlling
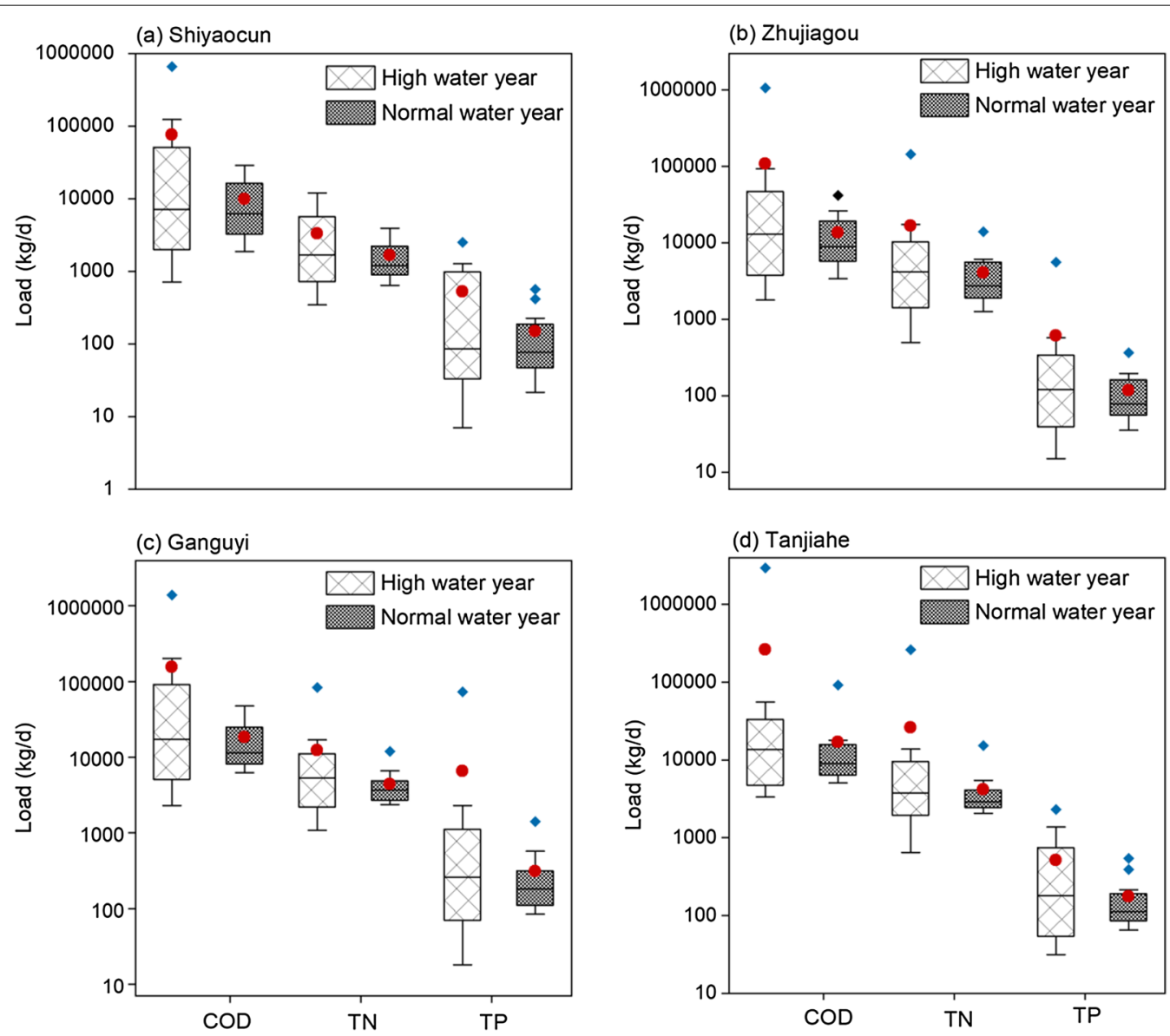

Fig. 8 Boxplots of COD, TN, and TP loads during flood and non-flood periods at four water quality monitoring stations: a Shiyaocun, b Zhujiagou, c Ganguyi, and $\mathbf{d}$ Tanjiahe. The horizontal lines represent (from the top) the maximum, the third quartile, the median, the first quartile and the minimum. The red circles represent average values, and the blue squares represent outliers 
measures. This also tells that a finer scale (e.g., day and hour) study of pollutant changes in an extreme hydrological event (i.e., before and after the flooding) deserves further investigation.

\section{Uncertainty analysis of the LOADEST modeling}

The performance of the load estimation method (LOADEST) is dependent on many factors including constituent type, streamflow characteristics, sampling frequency, and water-quality record consistency (Lee et al. 2016). In terms of regression models, the uncertainty may be higher because the LOADEST model assumes that all explanatory variables have zero error (Pellerin et al. 2014). In this study, the uncertainty of the LOADEST modeling deserves attention because the discrete and low sampling frequency of $\mathrm{TN}$ could affect the simulation accuracy, and the hydrological change could cause poor relations between constituent concentration and discharge. Further, the streamflow fluctuated greatly, resulting in greater residual errors at high streamflow, mainly because the regression model assumed a stationary concentration-flow relationship. For example, positive hysteresis occurs when constituent concentrations on the rising limb of a storm hydrograph are higher than those measured at equivalent flows on the falling limb (Amirreza et al. 2017). Therefore, it would be significant but challenging to improve the accuracy of load estimation methods. In addition, topography plays an important role in pollutant diffuse, and the combination of statistical models and watershed delineation would help identify contaminated areas and achieve load reduction targets based on water environmental capacity (Park et al. 2015). In the future study, the uncertainties in land surface conditions, hydrological processes and extreme hydrological events deserve to be investigated for better estimation of pollutant fluxes.

\section{Limitations}

We acknowledged that there are still a couple of limitations in terms of the method and data used. First, the PS load in each month was estimated using the product of the minimum concentration and the corresponding streamflow in the dry season (see "Quantification of PS and NPS pollutant loads" section). Although this approach was widely applied (Zhu et al. 2012, 2018; Ongley et al. 2010), it ignores the variation of PS load and thus may bring bias and uncertainties. Second, observations for the three water quality variables (i.e., COD, TN, and $\mathrm{TP}$ ) from five monitoring stations are quite limited (once a month) and thus may not be sufficient to represent the real situation. It is of significance to improve the quantity and quality of the measurement in a future study.

\section{Conclusions}

In this study, we investigated the spatiotemporal changes of pollutant loads by combining the hydrological model SWAT and the statistical water quality model LOADEST in the YanRB. We also quantified PS and NPS load using the characteristic load method. The temporal analysis indicated that the pollutant loads showed a slight upward trend at four of five stations (i.e., Ansai, Shiyaocun, Ganguyi, Tanjiahe), and reached the maximum in 2014 due to the high precipitation under the normal water year conditions. The seasonal proportions of TN and TP loads indicated that there was a relatively higher level of pollutant loads in summer, followed by autumn, due to the high flow and frequent agricultural practices in these two seasons. Therefore, the summer is the most important period for targeting riverine nutrient loads reduction for the NPS pollution dominated watershed. Further, we found that the pollutant loads were concentrated in July, with relatively higher rainfall, suggesting much attention should be given to this month and extreme rainfall. Our spatial result showed that the most polluted area was in the midstream area (around Ganguyi) where more attention and measures should be considered. The high-water year was 2013, and the loads in this typical year were almost 9 times that of other years, indicating the potential risk in wet years. In addition, we found that NPS pollution contributed substantially to loads of COD, TN, and TP. This study can provide a good reference to decisionmakers for sustainable water resources management of the Yan River Basin. However, addressing the limitations and determining the water environment capacity through integration of statistical and process models with intensive verification would be a good subject for future study.

\section{Appendix}

In order to assess model performance compared to observations, the following popular criteria were used in this study:

(I) The percentage bias (PBIAS) measures the average difference of the observed and simulated value. The optimal value of PBIAS is 0.0 , with low-magnitude values indicating accurate model simulation, while positive or negative values indicate overestimation or underestimation bias, respectively (Yapo et al. 1996):

$$
\text { PBIAS }=\frac{1}{n} \sum_{i=1}^{n}\left(\frac{Y_{i, \text { sim }}-Y_{i, \text { obs }}}{Y_{i, \text { obs }}} \times 100\right) .
$$

(II) The Nash-Sutcliffe efficiency (NSE) (Nash and Sutcliffe 1970) is a normalized statistic that measures the goodness of fit. If the efficiency becomes negative, 
model predictions are worse than a prediction performed using the average of all observations. While the efficiency is closer to 1 , corresponding to a perfect match of modeled to the observed data:

$$
\mathrm{NSE}=1-\frac{\sum_{i=1}^{n}\left(Y_{i, \mathrm{sim}}-Y_{i, \mathrm{obs}}\right)^{2}}{\sum_{i=1}^{n}\left(Y_{i, \mathrm{obs}}-\bar{Y}_{\mathrm{obs}}\right)^{2}} .
$$

(III) The $R^{2}$ reveals the strength and direction of a linear relationship between the simulated and observed value. The difference between the NSE and the $R^{2}$ is that the NSE can interpret model performance in replicating individually observed values, while the $R^{2}$ does not (Green and van Griensven 2008):

$$
R^{2}=\frac{\left(\sum_{i=1}^{n}\left(Y_{i, \mathrm{obs}}-\bar{Y}_{\mathrm{obs}}\right)\left(Y_{i, \mathrm{sim}}-\bar{Y}_{\mathrm{sim}}\right)\right)^{2}}{\sum_{i=1}^{n}\left(Y_{i, \mathrm{obs}}-\bar{Y}_{\mathrm{obs}}\right)^{2} \sum_{i=1}^{n}\left(Y_{i, \mathrm{sim}}-\bar{Y}_{\text {sim }}\right)^{2}} .
$$

(IV) The PPCC test by using the correlation coefficient $r$ between the ordered observation $X_{i}$ and the corresponding fitted quantiles $M_{i}$ was provided by Filliben (1975) for normality test. The corresponding fitted quantiles of this test are determined by plotting position for each observation. It is assumed that the observations could have been drawn from the fitted distribution if the value of $r$ is close to 1.0 :

$$
r=\frac{\sum_{i=1}^{n}\left(X_{i}-\bar{X}\right)\left(M_{i}-\bar{M}\right)}{\sqrt{\sum_{i=1}^{n}(X i-\bar{X})^{2} \sum_{i=1}^{n}(M i-\bar{M})^{2}}} .
$$

$X$ and $M$ denote the mean values of the observations $X_{i}$ and the fitted quantiles $M_{i}$, respectively, and $n$ is the sample size. The estimate of the order statistic median for $M_{i}$ is shown as follows:

$$
\begin{aligned}
& M_{i}=\Phi^{-1}\left(P_{i}\right), \\
& P_{i}=1-(0.5)^{\frac{1}{n}}, i=1, \\
& P_{i}=\frac{i-0.3175}{n+0.365}, i=2,3 \ldots n-1, \\
& P_{i}=(0.5)^{\frac{1}{n}}, i=n .
\end{aligned}
$$

$\Phi^{-1}$ is the inverse of cumulative distribution function.

\section{Supplementary Information}

The online version contains supplementary material available at https://doi. org/10.1186/s40562-022-00220-3.

Additional file 1: Fig. S1. Annual average loads of COD, TN, and TP at five stations. Black dots represented the annual average value $(\mathrm{kg} / \mathrm{d})$, red lines indicated linear tendency and significance from 2001-2014, and blue lines indicated linear tendency and significance from 2001-2018.

\section{Acknowledgements}

We thank the editor and the anonymous reviewers for their constructive comments and suggestions. We also thank the HPCC Platform in Xi'an Jiaotong University for computing equipment and computer maintenance.

\section{Authors' contributions}

YS collected hydrological and water quality data, implemented the study, and wrote the paper. YW designed and supervised this study, and checked/corrected all the versions of the manuscript. CS provided water quality data. FZ commented on earlier versions of the manuscript. JH commented on earlier versions of the manuscript. JC, LQ, and YL provided data and edited the texts. All authors read and approved the final manuscript.

\section{Funding}

The study was funded by the Key Laboratory of Eco-Environment and Meteorology for the Qinling Mountains and Loess Plateau, Shaanxi Meteorological Bureau (2021 K-6), the Strategic Priority Research Program of Chinese Academy of Sciences (XDB40020205), the 'Light of the West'talent program of the Chinese Academy of Science, the Key Research and Development Project in Shaanxi Province (S2020-YF-GHZD-0061), the Innovation Team of Shaanxi Province (2021TD-52), the Technology Innovation Center for Land Engineering and Human Settlements, Shaanxi Land Engineering Construction Group Co., Ltd and Xi'an Jiaotong University (201912131-B2), the National Thousand Youth Talent Program of China, and the Shaanxi Hundred Talent Program.

\section{Availability of data and materials}

The data supporting SWAT analyses can be accessed publicly from the link provided in this paper, and the simulation data are available from the corresponding author on reasonable request.

\section{Declarations}

\section{Competing interests}

The authors declared that they have no conflict of interests.

\section{Author details}

${ }^{1}$ Department of Earth and Environmental Science, Xi'an Jiaotong University, Xi'an 710049, Shaanxi Province, China. ${ }^{2}$ Technology Innovation Center for Land Engineering and Human Settlements, Shaanxi Land Engineering Construction Group Co. Ltd., Xi'an Jiaotong University, Xi'an, China. ${ }^{3}$ Shaanxi Provincial Academy of Environmental Sciences, Xi'an 710061, China. ${ }^{4}$ Department of Civil Engineering, The University of Hong Kong, Pokfulam, Hong Kong, China. ${ }^{5}$ Hohai University, Nanjing, China.

Received: 8 May 2021 Accepted: 1 February 2022

Published online: 19 February 2022

\section{References}

Amirreza S, Haw Y, Carlington W, Gregory MC, Wade C, Bahram M et al (2017) Effect of water quality sampling approaches on nitrate load predictions of a prominent regression-based model. Water 9:895

Arnold JG, Srinivasan R, Muttiah RS, Williams JR (1998) Large area hydrologic modeling and assessment part i: model development. JAWRA J Am Water Resour Assoc 34:1-17

Aulenbach BT (2013) Improving regression-model-based streamwater constituent load estimates derived from serially correlated data. J Hydrol 503:55-66 
Chen L, Liu R, Huang Q, Chen Y, Gao S, Sun C et al (2012) An integrated simulation-monitoring framework for nitrogen assessment: a case study in the Baixi watershed, China. Procedia Environ Sci 13:1076-1090

Chen D, Hu M, Guo Y, Dahlgren RA (2015a) Reconstructing historical changes in phosphorus inputs to rivers from point and nonpoint sources in a rapidly developing watershed in eastern China, 1980-2010. Sci Total Environ 533:196-204

Chen Y, Song X, Zhang Z, Shi P, Tao F (2015b) Simulating the impact of flooding events on non-point source pollution and the effects of filter strips in an intensive agricultural watershed in China. Limnology 16:91-101

Chen L, Sun C, Wang G, Xie H, Shen Z (2017) Event-based nonpoint source pollution prediction in a scarce data catchment. J Hydrol 552:13-27

Chen YP, Fu BJ, Zhao Y, Wang KB, Wang H (2020) Sustainable development in the yellow river basin: issues and strategies. J Cleaner Prod 263:121223

Cohn TA, Gilroy EJ, Baier WG (1992) Estimating fluvial transport of trace constituents using a regression model with data subject to censoring. The Survey 142-151

Dai X, Zhou Y, Ma W, Zhou L (2017) Influence of spatial variation in land-use patterns and topography on water quality of the rivers inflowing to Fuxian lake, a large deep lake in the plateau of southwestern China. Ecol Eng 99:417-428

Duan W, Takara K, He B, Luo P, Nover D, Yamashiki Y (2013) Spatial and temporal trends in estimates of nutrient and suspended sediment loads in the Ishikari river, Japan, 1985 to 2010. Sci Total Environ 461:499-508

Duan S, Powell RT, Bianchi TS (2014) High frequency measurement of nitrate concentration in the lower Mississippi river, USA. J Hydrol 519:376-386

Filliben JJ (1975) The probability plot correlation coefficient test for normality. Technometrics 17:111-117

Green CH, van Griensven A (2008) Autocalibration in hydrologic modeling: using swat2005 in small-scale watersheds. Environ Model Softw 23:422-434

Grygar TM, Elznicová J, Bábek O, Hošek M, Engel Z, Kiss T (2014) Obtaining isochrones from pollution signals in a fluvial sediment record: a case study in a uranium-polluted floodplain of the Ploučnice river, Czech republic. Appl Geochem 48:1-15

Guo Y, Chang Huang C, Pang J, Zhou Y, Zha X, Mao P (2016) Reconstruction palaeoflood hydrology using slackwater flow depth method in the Yanhe river valley, middle yellow river basin, China. J Hydrol 544:156-171

Hao FH, Yang ST, Cheng HG, Bu QS, Zheng LF (2006) A method for estimation of non-point source pollution load in the large-scale basins of China. Acta Sci Circum 26:375-383

Jiake LI, Huaien LI, Bing SH et al (2011) Effect of non-point source pollution on water quality of the weihe river. Int I Sediment Res 01:53-64

Jiang Y, Liu C, Hao S, Zhao H, Li X (2019) A framework to develop a watershed pollution load model for semiarid and semihumid areas. J Hydrol 579:124179

Junfu G, Zhanbin L, Zongping R (2016) Responses of runoff process to climate change and human activities in Yanhe river basin. Sci Soil Water Conserv 14:57-65

Lang M, Li P, Yan X (2013) Runoff concentration and load of nitrogen and phosphorus from a residential area in an intensive agricultural watershed. Sci Total Environ 458:238-245

Lee CJ, Hirsch RM, Schwarz GE, Holtschlag DJ, Preston SD, Crawford CG et al (2016) An evaluation of methods for estimating decadal stream loads. J Hydrol 542:185-203

$\mathrm{Li} \mathrm{H}$ (2000) Mean concentration method for estimation of nonpoint source load and its application. Actaentiae Circumstantiae 20:397-400

Lian Y, Sun M, Wang J, Luan Q, Gao X (2021) Quantitative impacts of climate change and human activities on the runoff evolution process in the yanhe river basin. Phys Chem Earth Parts a/b/c 122:102998

Lin C, Wu Z, Ma R, Su Z (2016) Detection of sensitive soil properties related to non-point phosphorus pollution by integrated models of SEDD and PLOAD. Ecol Ind 60:483-494

Lin C, Ma R, Xiong J (2018) Can the watershed non-point phosphorus pollution be interpreted by critical soil properties? A new insight of different soil p states. Sci Total Environ 628-629:870-881

Miao Y (2018) Hydrological elements variation feature analysis of the Yanhe river basin over the last 50 years. Geospatial Inf 16:58-60

Moriasi D, Arnold J, Van Liew M, Bingner R, Harmel RD, Veith T (2007) Model evaluation guidelines for systematic quantification of accuracy in watershed simulations. Trans ASABE 50
Nash JE, Sutcliffe JV (1970) River flow forecasting through conceptual models Part I-a discussion of principles. J Hydrol 10:282-290

Neitsch S, Arnold J, Kiniry J, Williams JR (2011) Soil and water asessment tool theoritical documentation: Version 2009, texas water resources institute technical report no. 406. Texas water resources institute, Texas a\&m university, Texas, USA

Oelsner GP, Stets EG (2019) Recent trends in nutrient and sediment loading to coastal areas of the conterminous us: insights and global context. Sci Total Environ 654:1225-1240

Ongley E, Zhang X, Yu T (2010) Current status of agricultural and rural non-point source pollution assessment in China. Environ Pollut 158:1159-1168

Park YS, Engel BA (2016) Identifying the correlation between water quality data and LOADEST model behavior in annual sediment load estimations. Water 8:368

Park Y, Engel B, Frankenberger J, Hwang H (2015) A web-based tool to estimate pollutant loading using LOADEST. Water 7:4858-4868

Pei X, Ding Q, Yang Y, Cheng J, Guo Q (2019) Change and influencing factors of water quality in yanhe river from 2013 to 2017. Bull Soil Water Conserv

Pellerin BA, Bergamaschi BA, Gilliom RJ, Crawford CG, Saraceno JF, Frederick CP et al (2014) Mississippi river nitrate loads from high frequency sensor measurements and regression-based load estimation. Environ Sci Technol 48:12612-12619

Runkel RL, Crawford CG, Cohn TA (2004) Load estimator (loadest): a fortran program for estimating constituent loads in streams and rivers

Schwarzenbach RP, Egli T, Hofstetter TB, Uv G, Wehrli B (2010) Global water pollution and human health. Annu Rev Environ Resour 35:109-136

Sharifi A, Yen H, Wallace CW, McCarty G, Crow W, Momen B et al (2017) Effect of water quality sampling approaches on nitrate load predictions of a prominent regression-based model. Water 9:895

Shi X, Li L, Zhang T (2015) Water pollution control action plan, a realistic and pragmatic plan-an interpretation of water pollution control action plan. Environ Protect Sci 41:1-3

Su C, Fu B, Lu Y, Lu N, Zeng Y, He A et al (2011) Land use change and anthropogenic driving forces: a case study in Yanhe river basin. Chin Geogr Sci 21:587

Sudheer K, Chaubey I, Garg V, Migliaccio K (2007) Impact of time-scale of the calibration objective function on the performance of watershed models. Hydrol Process 21:3409-3419

Sun P, Wu Y, Yang Z, Sivakumar B, Qiu L, Liu S et al (2019) Can the grain-forgreen program really ensure a low sediment load on the Chinese Loess Plateau? Engineering 5:855-864

Tong Y, Zhao Y, Zhen G, Chi J, Liu X, Lu Y et al (2015) Nutrient loads flowing into coastal waters from the main rivers of China (2006-2012). Sci Rep 5:16678

USEPA (2015) US Environmental Protection Agency Washington, DC

Wang Q, Yang Z (2016) Industrial water pollution, water environment treatment, and health risks in China. Environ Pollut 218:358-365

Wang H, Zening W, Caihong H, Xinzhong D (2015) Water and nonpoint source pollution estimation in the watershed with limited data availability based on hydrological simulation and regression model. Environ Sci Pollut Res 22:14095-14103

Wei M, Duan P, Gao P, Guo S, Li M (2020) Exploration and application of hydrochemical characteristics method for quantification of pollution sources in the danjiangkou reservoir area. J Hydrol 590:125291

Wu Y, Chen J (2013) Investigating the effects of point source and nonpoint source pollution on the water quality of the east river (Dongjiang) in south China. Ecol Ind 32:294-304

Wu L, Gao J-e, Ma X-y, Li D (2015) Application of modified export coefficient method on the load estimation of non-point source nitrogen and phosphorus pollution of soil and water loss in semiarid regions. Environ Sci Pollut Res 22:10647-10660

Wu L, Liu X, Ma XY (2016) Spatio-temporal variation of erosion-type non-point source pollution in a small watershed of hilly and gully region, Chinese Loess Plateau. Environ Sci Pollut Res 23:10957-10967

Wu L, He Y, Ma X (2020) Using five long time series hydrometeorological data to calibrate a dynamic sediment delivery ratio algorithm for multi-scale sediment yield predictions. Environ Sci Pollut Res 27:1-16

Xia Y, Zhang M, Tsang DC, Geng N, Lu D, Zhu L et al (2020) Recent advances in control technologies for non-point source pollution with nitrogen and phosphorous from agricultural runoff: current practices and future prospects. Appl Biol Chem 63:1-13 
Yang X, Sun W, Li P, Mu X, Gao P, Zhao G (2019) Integrating agricultural land, water yield and soil conservation trade-offs into spatial land use planning. Ecol Ind 104:219-228

Yapo PO, Vijai H et al (1996) Automatic calibration of conceptual rainfall-runoff models: sensitivity to calibration data. J Hydrol 181:23-48

Zeng Z, Luo W-G, Wang Z, Yi F-C (2021) Water pollution and its causes in the tuojiang river basin, China: an artificial neural network analysis. Sustainability 13:792

Zhang S, Wu Y, Sivakumar B, Mu X, Zhao F, Sun P et al (2019) Climate changeinduced drought evolution over the past 50 years in the southern Chinese Loess Plateau. Environ Model Softw 122:104519

Zhao J, Feng X, Deng L, Yang Y, Zhao Z, Peng C, et al. (2020a) Quantifying the effects of vegetation restorations on the soil erosion export and nutrient loss on the loess plateau. Front Plant Sci 11

Zhao MM, Wang S-m, Chen Y-p, Wu J-h, Xue L-g, Fan TT (2020b) Pollution status of the yellow river tributaries in middle and lower reaches. Sci Total Environ 722:137861

Zhou L, Li Y (2018) A study on China's water pollution status and water environment management strategy. Environ Dev

Zhu Y, Chen L, Wei G, Li S, Shen Z (2019) Uncertainty assessment in baseflow nonpoint source pollution prediction: the impacts of hydrographic separation methods, data sources and baseflow period assumptions. J Hydrol 574:915-925

Zhu L, Huaien LI, Jiake LI (2012) Estimation of pollution load above linjiacun section in the weihe river watershed based on characteristic load method. J Xi'an Univ Technol

Zhu L, Song J, Liu W (2018) Evaluating nh3-n pollution load of weihe river watershed above tongguan section by characteristic section load method

Zou L, Liu Y, Wang Y, Hu X (2020) Assessment and analysis of agricultural non-point source pollution loads in China: 1978-2017. J Environ Manag 263:110400

\section{Publisher's Note}

Springer Nature remains neutral with regard to jurisdictional claims in published maps and institutional affiliations.

\section{Submit your manuscript to a SpringerOpen ${ }^{\circ}$ journal and benefit from:}

- Convenient online submission

- Rigorous peer review

- Open access: articles freely available online

- High visibility within the field

- Retaining the copyright to your article 